\title{
Posterior tooth morphology and lower incisor crowding
}

\author{
Anwar A. Shah*, Claire Elcock, and Alan H. Brook \\ Department of Oral Health and Development, School of Clinical Dentistry, University of Sheffield, United \\ Kingdom
}

ABSTRACT Frequently, only the mesiodistal dimensions of mandibular posterior teeth have been investigated in relation to lower incisor crowding. The aim of the present study was to investigate any relationship between lower incisor crowding and mesiodistal widths, buccolingual dimensions, occlusal area and occlusal perimeter of mandibular posterior teeth. Mandibular dental casts of 50 Caucasians (25 males and 25 females) were used. Mesiodistal widths, buccolingual dimensions, occlusal area and occlusal perimeter were measured using

Crowding in the lower arch most commonly is seen in the anterior segment. The etiology of dental crowding seems to be multifactorial and tooth morphology has been suggested as an important component. No single factor has so far been demonstrated to be a major cause of anterior crowding.

Some workers have found a positive correlation between lower incisor and posterior tooth mesiodistal width (MD) and lower arch crowding (Peck and Peck, 1972a,b; Norderval et al., 1975; Doris et al., 1981); others (Mills, 1964; Howe et al., 1983; Radnzic, 1988) have failed to find evidence of such an association. There is coordinated development between different tooth types in the dental arch in size, such that subjects with larger mesiodistal dimensions of lower incisors may have larger tooth size elsewhere in the dental arch (Harris and Bailit, 1988). However, studies of lower incisor crowding and posterior tooth morphology have been limited to measuring only the mesiodistal width. Therefore, the aim of this study was to investigate the relationship between lower incisor crowding and the occlusal surface area, buccolingual and mesiodistal dimensions of mandibular posterior teeth.

\section{MATERIALS AND METHODS}

The sample consisted of dental casts of the mandibular teeth of 50 adult Caucasians ( 25 males and 25 females).

A computerised image analysis technique was used to analyse the dental casts (Brook et al., 1998). The apparatus consisted in part of a 32-bit digital camera image analysis techniques. Lower incisor crowding was determined using (1) Little's irregularity index and (2) anterior-tooth size arch length discrepancy. Using Pearson correlation, the occlusal area, perimeter, mesiodistal widths and buccolingual dimensions of the lower first molar were significantly, positively correlated with Little's irregularity index. The significant correlation between occlusal area and crowding did not appear to be secondary to larger mesiodistal widths. Dental Anthropology 2005;18(2):37-42.

(Kodak, Nikon DCS 410). Adobe PhotoShop (version 5.0, Adobe Systems Ltd., Europe) was used to acquire images of the teeth. From all models an occlusal image of each posterior tooth was captured, starting from the lower left first permanent molar to the lower right first permanent molar. For all images the position of the tooth was such that the lens of the camera was focused at right angles to the long axis of the clinical crown.

The following measurements were carried out using Image Pro Plus (version 4.0, Media Cybernetics, USA):

1. Area and perimeter: The maximal contour of the occlusal surface of the posterior teeth (from first molar to canine) was traced (Fig. 1) giving rise to area (A) and perimeter $(\mathrm{P})$ measurements.

2. Mesiodistal width (MD): This was measured between the anatomical mesial and distal contacts (Fig. 1).

3. Buccolingual diameter (BL): The buccolingual diameter was measured as perpendicular to and at the midpoint of the mesiodistal diameter (Fig. 1).

4. Lower incisor crowding: Little's irregularity index (II5; Little, 1975) and anterior tooth size-arch length discrepancy (ATSALD) were used to quantify lower incisor crowding. The II5 is the sum of five contact

*Correspondence to: Anwar Shah, Department of Oral Health and Development, School of Clinical Dentistry, University of Sheffield, S10 2TA, United Kingdom

Email: a.a.shah@sheffield.ac.uk 


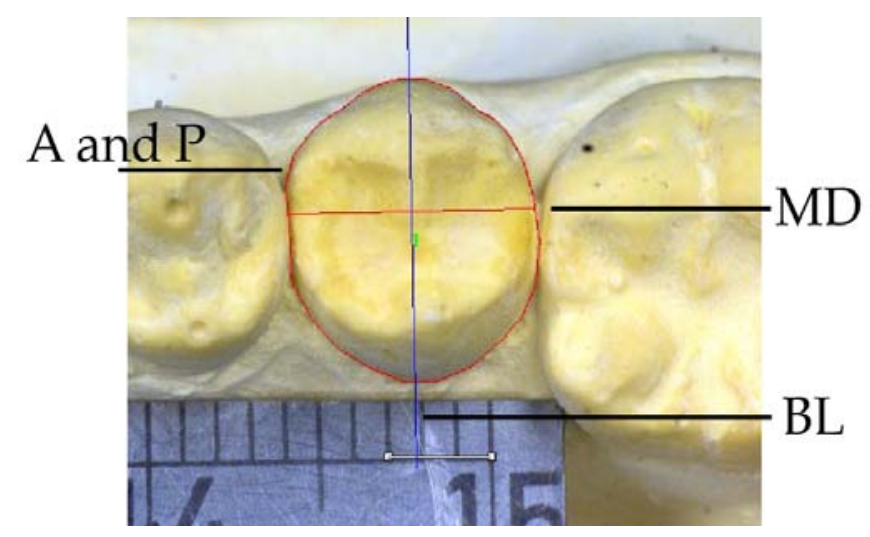

Fig. 1. An image of a lower right second premolar with mesiodistal (MD), buccolingual (BL), area (A) and perimeter $(\mathrm{P})$ dimensions. The steel rule allows linear calibration of each image.

displacements between the lower anterior teeth. It was measured manually using digital calipers (Mitutoyo, Japan).

The ATSALD was measured as the difference between the sum of the individual mesiodistal widths of the four lower incisors and the dental arch length, using the image analysis method. The latter was measured on both sides of the arch from the mesial contact point of canine to the contact between the mesial contact points of central incisors. If there was no contact between the central incisors, it was measured between the mesial contact of the canine and the mesial contact point of the central incisor, which was thought to be in normal position.

\section{Repeatability}

All teeth were re-imaged and re-measured on a separate occasion after an interval of one week, to assess the reliability of the method.

The error of II5 was calculated by re-measuring the index manually, on ten models on two separate occasions, one week apart. To examine the reliability of ATSALD, twenty models were re-imaged and remeasured after a one-week interval.

Systematic error was calculated using paired ttests, and random error was estimated with intra-class correlation coefficients. Descriptive statistics and the Pearson and Spearman correlation coefficients were used to assess the correlation between lower incisor crowding and posterior tooth parameters.

\section{RESULTS}

\section{Measurement reliability}

From Table 1 it can be seen that the range of error variance for different tooth types for MD dimensions of posterior teeth was between $3 \%$ and $6 \%$, and for BL tooth dimensions of posterior teeth between $3 \%$ and $10 \%$. For area and perimeter measurements error variance ranged from 1 to $3 \%$ among the different tooth types. The mean differences between the first and second measurements after re-imaging the teeth were not statistically significant.

\section{Tooth dimensions and crowding indices}

The mean and range of MD, BL, A and P for canines, premolars and first molars of males are given in Table 2 and for females in Table 3.

In the male group some first molar and second premolar variables showed significant correlations with the crowding indices (Table 4). For the occlusal surface of first molars $\mathrm{MD}, \mathrm{BL}, \mathrm{A}$ and $\mathrm{P}$ were significantly correlated at the $5 \%$ level with II5 (Table 4). First molar MD dimension showed significant correlation with ATSALD $(P=0.04)$, and A and P approached significance $(0.10>\mathrm{P}>0.05)$. However, the correlation coefficients between these variables and the crowding indices ranged from 0.39 to 0.48 , indicating that although an association may exist, it is not high.

From Table 4 it can be seen that for second premolars $\mathrm{MD}$ and A were significantly correlated with II5, with $\mathrm{P}$ approaching significance $(0.10>\mathrm{P}>0.05)$. Only $\mathrm{MD}$ approached a significant association $(P=0.06)$ with ATSALD, and the remaining three variables of the second premolar showed no evidence of association with ATSALD. First premolar and canine variables showed no significant correlation.

In contrast, in the female group no evidence was found of an association with either II5 or ATSALD. The Pearson correlation coefficients ( $\mathrm{r}$ ) ranged from zero to

TABLE 1. Intraclass correlation coefficients for re-imaging error of posterior teeth ${ }^{1}$

\begin{tabular}{llllc}
\hline Tooth type & MD & BL & Area & Perimeter \\
\hline First molar & $0.96(4 \%)$ & $0.90(10 \%)$ & $0.98(2 \%)$ & $0.97(3 \%)$ \\
Second premolar & $0.94(6 \%)$ & $0.97(3 \%)$ & $0.98(2 \%)$ & $0.97(3 \%)$ \\
First premolar & $0.95(5 \%)$ & $0.95(5 \%)$ & $0.98(2 \%)$ & $0.98(2 \%)$ \\
Canine & $0.97(3 \%)$ & $0.97(3 \%)$ & $0.99(1 \%)$ & $0.99(1 \%)$ \\
\hline
\end{tabular}

${ }^{1}$ Figures in parenthesis indicate proportion of variance in measurements due to method error 
TABLE 2. Measurements (in $\mathrm{mm}$ or $\mathrm{mm}^{2}$ ) for first molar, premolars and canine in the male group

\begin{tabular}{|c|c|c|c|c|c|c|c|c|}
\hline & \multicolumn{2}{|c|}{ First molar } & \multicolumn{2}{|c|}{ Second premolar } & \multicolumn{2}{|c|}{ First premolar } & \multicolumn{2}{|c|}{ Canine } \\
\hline & Mean & Range & Mean & Range & $\overline{\text { Mean }}$ & Range & $\overline{\text { Mean }}$ & Range \\
\hline MD & 10.88 & $9.8-12.13$ & 7.19 & $6.27-8.14$ & 7.11 & $6.21-8.01$ & 6.91 & $5.70-7.89$ \\
\hline BL & 10.49 & $9.35-11.86$ & 8.53 & $7.21-9.62$ & 7.96 & $6.66-9.29$ & 7.90 & $5.82-9.57$ \\
\hline A & 100.64 & $84.8-124.9$ & 50.04 & $37.62-67.21$ & 44.17 & $32.9-54.73$ & 41.6 & $33.45-56.4$ \\
\hline $\mathrm{P}$ & 35.58 & $23.7-40.18$ & 25.37 & $21.11-29.44$ & 23.79 & $20.45-26.59$ & 23.98 & $21.19-35.5$ \\
\hline
\end{tabular}

0.37 (Table 5).

Spearman's correlation coefficients were calculated for all the significant results to check that these were not due to outliers (Table 6). The correlation between II5 and first molar variables remained significant. However, the correlation between MD of first molar and ATSALD, and MD and A of second premolar and II5 lost significance. This showed that the latter significant result was probably due to the presence of an outlier in the data.

\section{DISCUSSION}

In the present study, the error variance for posterior tooth variables did not exceed $10 \%$ for different tooth types. Crown area represented the overall size of the tooth and takes into account both MD and BL dimensions. The area of the posterior teeth showed the least error variation in relation to the total variation in the materials studied (1 to $2 \%$ ). This can be interpreted as suggesting that crown area would be a better single indicator of biological variation than either MD or BL alone, where the error variation was 3 to $10 \%$ of the total variation. However, combination of the parameters measured is important in considering the shape of teeth, as two teeth with different shapes may have similar area measurements.

Lower arch crowding is important not only from a clinical point of view, but it also has implications in understanding the controlling factors of tooth size. Begg (1954) reported that there was less crowding in the Aborigines and he attributed this to greater interproximal attrition, due to ingestion of coarse food in that population. Lower incisor crowding has been quantified in different ways, and Little's irregularity index (1975) and ATSALD are the two methods commonly used in orthodontic literature. Even the
ATSALD has been measured in many ways by different investigators. Harris (1987) has shown that II5 and ATSALD may not measure the same thing and the present study lends support to that suggestion.

The results show that area of posterior teeth is an important variable when investigating lower incisor crowding. Previous studies have reported a positive correlation between lower incisor crowding and MD dimension of posterior teeth, and this association was interpreted as larger teeth occupying more space in the dental arch, which may result in crowding. In this study, however, we have shown that, in males in addition to $\mathrm{MD}$ and BL dimensions, posterior occlusal area may be associated with lower incisor crowding, and the strengths of the association of these variables with crowding are not substantially different from each other (Table 4).

In the female group, there was no association of posterior tooth area with lower incisor crowding. It cannot be explained readily whether such an association did not exist in the first place or whether any such association was undetected.

The work opens a new dimension for future studies, as the association of MD and lower incisor crowding may be secondary to the association of larger posterior tooth area. This is partially supported by previous work (Shah, 2000) where 44 variables were measured on lower study models. The number of variables was subsequently reduced to 5 by using principal component analysis. When regression analysis was performed, area and BL width of posterior teeth entered before MD dimension in the regression equation. It was further shown that when area for posterior teeth was not included in the regression analysis, the BL dimension preceded the MD dimension in significance.

While the positive association of the MD of molars

TABLE 3. Measurements (in mm or $\mathrm{mm}^{2}$ ) for first molar, premolars and canine in the female group

\begin{tabular}{|c|c|c|c|c|c|c|c|c|}
\hline & \multicolumn{2}{|c|}{ First molar } & \multicolumn{2}{|c|}{ Second premolar } & \multicolumn{2}{|c|}{ First premolar } & \multicolumn{2}{|c|}{ Canine } \\
\hline & Mean & Range & Mean & Range & Mean & Range & Mean & Range \\
\hline MD & 10.41 & $9.02-11.49$ & 6.91 & $6.20-7.74$ & 6.86 & $6.11-7.79$ & 6.45 & $5.56-7.48$ \\
\hline BL & 10.22 & $9.00-11.19$ & 8.32 & $7.14-9.59$ & 7.60 & $6.67-8.3 / 9$ & 7.38 & $6.30-8.21$ \\
\hline A & 94.27 & 77.87-105.00 & 46.48 & 36.84-56.87 & 40.51 & $31.77-47.64$ & 36.49 & $25.81-46.01$ \\
\hline $\mathrm{P}$ & 34.87 & 31.79-36.90 & 24.42 & 21.74-27.10 & 22.78 & $20.16-24.71$ & 21.80 & $18.40-24.41$ \\
\hline
\end{tabular}


TABLE 4. Pearson correlation coefficients ( $r$ ) between lower incisor crowding and lower first molar, premolars, and canine in males

\begin{tabular}{lccccc}
\hline & Variable & II5 (r value) & P value & ATSALD (r value) & P value \\
\hline First molar & MD & 0.48 & $0.02^{*}$ & 0.40 & $0.04^{*}$ \\
& BL & 0.44 & $0.03^{*}$ & 0.29 & 0.15 \\
& $\mathrm{~A}$ & 0.46 & $0.02^{*}$ & 0.37 & 0.07 \\
Second premolar & $\mathrm{P}$ & 0.39 & $0.05^{*}$ & 0.37 & 0.09 \\
& $\mathrm{MD}$ & 0.42 & $0.04^{*}$ & 0.38 & 0.06 \\
& $\mathrm{BL}$ & 0.31 & 0.13 & 0.20 & 0.16 \\
First premolar & $\mathrm{A}$ & 0.39 & $0.05^{*}$ & 0.30 & 0.15 \\
& $\mathrm{P}$ & 0.38 & 0.07 & 0.27 & 0.19 \\
& $\mathrm{MD}$ & 0.26 & 0.21 & 0.33 & 0.10 \\
Canine & $\mathrm{BL}$ & 0.10 & 0.64 & 0.04 & 0.42 \\
& $\mathrm{~A}$ & 0.16 & 0.44 & 0.17 & 0.29 \\
& $\mathrm{P}$ & 0.20 & 0.34 & 0.22 & 0.41 \\
& $\mathrm{MD}$ & 0.12 & 0.57 & 0.17 & 0.79 \\
& $\mathrm{BL}$ & 0.05 & 0.82 & 0.05 & 0.57 \\
\hline
\end{tabular}

${ }^{*} \mathrm{P}<0.05$

with lower incisor crowding may be readily understood, the association of occlusal area of molars merits further consideration.

The literature indicates that, with age, mandibular intermolar and interpremolar widths either increase or remain unchanged (Harris, 1997; Bishara et al., 1994, 1997). If the buccal teeth are drifting away from the midline, then the supporting bone ought to remodel to accommodate them. Data show that this does occur and the changes are in the predicted direction (Enlow and
Harris, 1964; Enlow et al., 1976; Israel, 1979). The upper molars are slanted buccally and the increase in intermolar and interpremolar widths may be due to displacement of molars buccally by the force of occlusion (Harris, 1997). However, Haas (1980) found that by expanding the upper arch, lower intermolar and interpremolar widths also increased and it was suggested that this might be as a consequence of the altered forces of occlusion and muscle balance, with buccal tension diminishing and lingual pressure increasing. In postretention studies,

TABLE 5. Pearson correlation coefficients ( $r$ ) between incisor crowding and lower first molar, second premolars, and canine in females

\begin{tabular}{|c|c|c|c|c|c|}
\hline & Variable & $\begin{array}{c}\text { II5 } \\
\text { (r value) }\end{array}$ & $P$ value & $\begin{array}{l}\text { ATSALD } \\
\text { ( } \mathrm{r} \text { value) }\end{array}$ & P value \\
\hline \multirow[t]{4}{*}{ First molar } & MD & 0.02 & 0.92 & 0.12 & 0.56 \\
\hline & BL & 0.02 & 0.93 & 0.21 & 0.32 \\
\hline & A & 0.05 & 0.81 & 0.11 & 0.60 \\
\hline & $\mathrm{P}$ & 0.11 & 0.58 & 0.05 & 0.80 \\
\hline \multirow[t]{4}{*}{ Second premolar } & MD & 0.12 & 0.4 & 0.37 & 0.07 \\
\hline & BL & 0.01 & 0.95 & 0.23 & 0.28 \\
\hline & A & 0.00 & 0.98 & 0.26 & 0.21 \\
\hline & $\mathrm{P}$ & 0.00 & 0.99 & 0.24 & 0.24 \\
\hline \multirow[t]{4}{*}{ First premolar } & MD & 0.02 & 0.93 & 0.21 & 0.31 \\
\hline & BL & 0.01 & 0.95 & 0.19 & 0.37 \\
\hline & A & 0.12 & 0.35 & 0.19 & 0.36 \\
\hline & $\mathrm{P}$ & 0.12 & 0.56 & 0.17 & 0.40 \\
\hline \multirow[t]{4}{*}{ Canine } & MD & 0.02 & 0.92 & 0.17 & 0.41 \\
\hline & BL & 0.19 & 0.36 & 0.21 & 0.31 \\
\hline & A & 0.04 & 0.83 & 0.23 & 0.26 \\
\hline & $\mathrm{P}$ & 0.05 & 0.80 & 0.24 & 0.25 \\
\hline
\end{tabular}


TABLE 6. Spearman correlation coefficients $(r)$ between incisor crowding and lower first molar and second premolar variables in males.

\begin{tabular}{lccccc}
\hline & Variable & II5 $(\mathrm{r})$ & P value & ATSALD $(\mathrm{r})$ & P value \\
\hline First molar & MD & 0.50 & $0.01^{*}$ & 0.23 & 0.20 \\
& BL & 0.45 & $0.02^{*}$ & 0.24 & 0.25 \\
& $\mathrm{~A}$ & 0.48 & $0.01^{*}$ & 0.30 & 0.14 \\
Second premolar & P & 0.38 & 0.06 & 0.31 & 0.13 \\
& MD & 0.29 & 0.15 & 0.38 & 0.06 \\
& BL & 0.33 & 0.10 & 0.20 & 0.16 \\
& A & 0.31 & 0.13 & 0.30 & 0.15 \\
\hline
\end{tabular}

lower incisor alignment appears to be more stable in cases where upper arch expansion has been carried out (Moussa et al., 1995; Elms et al., 1996; Azizi et al., 1999; Shah 2003). At the same time, arch length and intercanine width decrease. We also know that posterior teeth move forward as a result of mesial drift with age (Begg, 1954; Beek, 1979) and, except for the increase in intermolar and interpremolar widths, all the remaining phenomenons will obviously have an adverse effect on lower incisor alignment. It may be that the simultaneous increase in intermolar and interpremolar width results in less incisor crowding.

Wolpoff (1971) concluded that as the roots of the posterior teeth are inclined forward in the jaws, so chewing forces create a mesial force vector. Therefore, the greater the chewing forces, which are determined by the nature of the diet, the higher the mesial force vector. However, as pressure is force per unit area, theoretically one would expect less pressure application to posterior teeth having a larger occlusal area, assuming there will be larger contact areas in the latter. This would cast doubt on the speculation that chewing forces might be associated with lower incisor crowding and/or mesial migration of the posterior teeth. This is supported in the present study where a larger occlusal area was positively associated with lower incisor crowding. This is further supported by Hidaka et al. (1999) who found that when the bite force increased with clenching intensity, occlusal contact area on the whole arch increased but the mean bite pressure (bite force per contact area) remained unchanged.

Therefore, the effect of a larger occlusal area may be operating by different mechanisms. Two possible mechanisms can be offered where larger molar occusal area may cause more lower incisor crowding:

1. Potential for buccal expansion may be reduced with larger posterior tooth area. Firstly, the morphology of the crown or root of posterior teeth associated with larger posterior tooth area may not allow the buccal movement of molars and the compensatory mechanism of an increase in intermolar and interpremolar widths does not operate. Secondly, there may be a difference in the path of eruption induced by a particular morphology and the posterior teeth might have less potential for buccal expansion. Thirdly, there may be an alteration in the direction of occlusal forces associated with larger posterior tooth area.

2. Mesial migration of the posterior teeth may be accelerated. Mesial migration may increase due to a larger posterior tooth area. This affect would not occur due to an increased bite force, but may be due to alteration in the directions of occlusal forces or due to alteration in the path of eruption of the posterior teeth.

For the posterior tooth variables in the female group, none was significantly correlated with the crowding indices. Why the posterior occlusal area in the female group showed no significant correlation with lower incisor crowding cannot be established. The ages of male and female subjects were comparable, but the crowding scores in the male group were higher than in the female group (Shah et al., 2003). The difference in crowding between the two groups may have resulted in different relationships.

In the literature, contact area tightness has been investigated in relation to various parameters, such as head posture, tooth type, location in the jaw and time of day (Southard et al., 1990; Dorfer et al., 2000). However, there is no literature to investigate the relationship between posterior tooth area and the contact area tightness between adjacent teeth. It would be worthwhile to investigate any association between posterior tooth occlusal area and the contact area tightness pressure, when a given amount of bite force is applied on the molar teeth and a pilot study is being currently formulated.

\section{CONCLUSIONS}

1. Image analysis is a reliable technique for measuring the area, perimeter, $\mathrm{MD}$ and $\mathrm{BL}$ dimensions of posterior teeth.

2. Lower incisor crowding was associated in this study with mandibular posterior tooth area, $\mathrm{MD}$ and $\mathrm{BL}$ dimensions in males. 


\section{LITERATURE CITED}

Azizi M, Shrout MK, Haas AJ, Russelll CM, Hamilton EH. 1999. A retrospective study of Angle class 1 malocclusions treated orthodontically without extractions using two palatal expansion methods. Am J Orthod Dentofacial Orthop 116:101-107.

Beek HV. 1979. The transfer of mesial drift potential along the dental arch in Macaca irus: an experimental study of tooth migration rate related to the horizontal vectors of occlusal forces. Eur J Orthod 1:125-129.

Begg PR. 1954. Stone age man's dentition. Am J Orthod 40:298-312, 373-383.

Bishara SE, Jakobsen JR, Treder JE, Nowak K. 1997. Arch width changes from 6 weeks to 45 years of age. Am J Orthod Dentofacial Orthop 111:401-409.

Bishara SE, Treder JE, Jakobsen JR. 1994. Facial and dental changes in adulthood. Am J Orthod Dentofacial Orthop 106:175-186.

Brook AH, Smith RN, Elcock C, Al-Sharood MH, Shah AA, Karmo M. 1998. The measurement of tooth morphology: development and validation of a new image analysis system. In: Mayhall JT, Heikkinen T, editors. Dental morphology 1998. Oulu: Finland: Oulu University Press, p 380-387.

Dörfer CE, von Bethlenfalvy ER, Staehle HJ, Pioch T. 2000. Factors influencing proximal dental contact strengths. Eur J Oral Sci 108:368-377.

Doris JM, Bernard BW, Kuftinec MM. 1981. A biometric study of tooth size and dental crowding. Am J Orthod 79:326-336.

Elms TN, Buschang PH, Alexander RG. 1996. Long-term stability of Class II, division 1, nonextraction cervical face-bow therapy: 1. Model analysis. Am J Orthod Dentofacial Orthop 109:271-276.

Enlow DH, Bianco HJ, Eklund S. 1976. The remodelling of the edentulous mandible. J Prosth Dent 36:685693.

Enlow DH, Harris DB. 1964. A study of the postnatal growth of the human mandible. Am J Orthod 50: 25-50.

Haas AJ. 1980. Long term posttreatment evaluation of rapid palatal expansion. Angle Orthod 50:189-217.

Harris EF. 1997. A longitudinal study of arch size and form in untreated adults. Am J Orthod Dentofacial Orthop 111:419-427.

Harris EF, Bailit HL. 1988. A principal components analysis of human odontometrics. Am J Phys Anthropol 75:87-99.

Harris EF, Vaden JL, Williams RA. 1987. Lower incisor space analysis: a contrast of methods. Am J Orthod
Dentofacial Orthop 92:375-380.

Hidaka O, Iwasaki M, Saito M, Morimoto T. 1999. Influence of clenching intensity on bite force balance, occlusal contact areas, and average bite pressure. J Dent Res 78:1336-1344.

Howe RP, McNamara JA, O'Connor KA. 1983. An examination of dental crowding and its relationship to tooth size and arch dimension. Am J Orthod 83:363-373.

Israel H. 1979. Evidence for continued apposition of adult mandibular bone from skeletalized materials. J Prosth Dent 41:101-104.

Little RM. 1975. The irregularity index: a quantitative score of mandibular anterior alignment. Am J Orthod 68:554-563.

Mills LF. 1964. Arch width, arch length, and tooth size in young adult males. Angle Orthod 34:124-129.

Moussa R, O'Reilly MT, Close JM. 1995. Long-term stability of rapid palatal expander treatment and edgewide mechanotherapy. Am J Orthod Dentofacial Orthop 108:478-488.

Norderval K, Wisth PJ, BoeOE. 1975. Mandibular anterior crowding in relation to tooth size and craniofacial morphology. Scand J Dent Res 83:263-273.

Peck S, Peck H. 1972a. Crown dimensions and mandibular incisor alignment. Angle Orthod 42:148153.

Peck H, Peck S. 1972b. An index for assessing tooth shape deviations as applied to the mandibular incisors. Am J Orthod 61:384-401.

Radnzic D. 1988. Dental crowding and its relationship to mesiodistal crown diameters and arch dimensions. Am J Orthod Dentofacial Orthop 94:50-56.

Shah AA. 2000. An investigation of the relationship between mandibular tooth morphology and lower incisor crowding using a new image analysis system. Unpublished Ph.D. dissertation, University of Sheffield, England.

Shah AA. 2003. Postretention changes in mandibular crowding: a review of the literature. Am J Orthod Dentofacial Orthop 124:298-308.

Shah AA, Elcock C, Brook AH. 2003. Relationship between incisor crown shape and crowding. Am J Orthod Dentofacial Orthop 123:562-567.

Southard TE, Southard KA, Tolley EA. 1990. Variation of aproximal tooth contact tightness with postural change. J Dent Res 69:1776-1779.

Wolpoff MH. 1971. Interstitial wear. Am J Phys Anthropol 34:205-228. 